\title{
ACASO E RELAÇÕES DE GÊNERO EM NARRATIVAS SOBRE A HISTÓRIA DE CURSOS DE FORMAÇÃO DE PROFESSORES DE MATEMÁTICA EM MINAS GERAIS: MONTES CLAROS E GOVERNADOR VALADARES*
}

\author{
Maria Laura Magalhães Gomes \\ Ana Catarina Cantoni Roque \\ Shirley Patrícia Nogueira de Castro e Almeida
}

\begin{abstract}
Resumo
O texto focaliza o acaso em aspectos ligados às relações de gênero que emergiram da produção intencional de documentos oportunizada pela mobilização da História Oral em duas pesquisas de doutorado sobre a história de dois cursos de licenciatura em Matemática fundados no final dos anos 1960 no estado de Minas Gerais. São os cursos de Governador Valadares, na instituição particular que se transformou na atual Univale (Universidade do Vale do Rio Doce), e de Montes Claros, na faculdade que posteriormente se integrou à Unimontes (Universidade Estadual de Montes Claros). Embora os roteiros utilizados nas entrevistas de ambas as investigações não tenham tido o propósito de conhecer aspectos das relações de gênero que permearam as trajetórias de criação e desenvolvimento desses cursos, tais aspectos se evidenciaram nas narrativas dos entrevistados. Quatro pontos referentes aos dois cursos são destacados no texto: o papel de homens e mulheres na criação das instituições e dos cursos; atitudes de professores e professoras, alunos e alunas na licenciatura em Matemática; relações entre homens, mulheres e Matemática; e vidas pessoais de professores e professoras, alunos e alunas.
\end{abstract}

\section{Introdução}

As pesquisas de Roque (2019) e Castro e Almeida (2015) tiveram como objeto as trajetórias de dois cursos de formação de professores de Matemática estabelecidos na década de 1960 no estado de Minas Gerais, em duas cidades: Montes Claros e Governador Valadares. O curso de Governador Valadares, investigado por Roque, foi realizado na instituição privada hoje denominada Univale (Universidade Vale do Rio Doce) e atualmente encontra-se extinto. Já o de Montes Claros, pesquisado por Castro e Almeida e ainda em atividade, está situado na Unimontes (Universidade Estadual de Montes Claros). Ambos os estudos fizeram uso da metodologia da História Oral, com a realização de um grande número de entrevistas com professores e estudantes que participaram de diferentes etapas nas instituições envolvidas em um período de 30 anos (1960-1990) em Montes Claros e 44 anos (1968-2012) em Governador Valadares.

Os roteiros utilizados nas entrevistas de ambas as investigações foram produzidos especificamente para a obtenção de informações sobre os cursos investigados e não houve,

\footnotetext{
* DOI - 10.29388/978-65-86678-51-2-0-f.551-574
} 
na ocasião, a intenção de se buscar conhecer aspectos das relações de gênero que permearam as trajetórias de criação e desenvolvimento desses cursos. Assim, o roteiro de Castro e Almeida (2015) contemplou os seguintes tópicos: o contexto do surgimento, nos anos 1960, da primeira instituição de ensino superior do norte de Minas Gerais; a transição, nos anos 1990, da Fundação Norte Mineira de Ensino Superior (Funm) para a Universidade Estadual de Montes Claros (Unimontes); a criação, em 1968, de um curso de formação de professores de Matemática; o processo de formação de professores de Matemática (1960-1990); os elementos que compunham a cultura acadêmica do curso pesquisado (projetos pedagógicos, diários de classe, planos de ensino, livros didáticos) e, finalmente, a análise do que constituía, na visão dos colaboradores da pesquisa, um bom professor de Matemática e sua prática.

Já Roque (2019) construiu um roteiro que focalizava principalmente: a formação acadêmica e experiência profissional do entrevistado ou entrevistada; o período de vínculo com o curso, como docente ou discente; a estrutura curricular do curso; a bibliografia e as metodologias utilizadas nas aulas; a inserção dos egressos na carreira do magistério, as características dos discentes; a importância do curso para a cidade e região. Para os docentes foi pedido, ainda, que falassem sobre a forma de ingresso na instituição, sobre sua concepção acerca da formação de professores de Matemática e, para aqueles que atuaram nos primeiros anos do curso, sobre as motivações para sua criação.

Como documentos fundamentais para investigações conduzidas anteriormente, as entrevistas e os textos delas decorrentes testemunham como as pessoas escutadas se viam, viviam e atuavam profissionalmente em dado período e lugar e, por isso, constituem fontes historiográficas (GARNICA; VIANNA, 2019). Desse modo, desde que se garantam os cuidados em relação à ética, é legítimo lançar mão dessas fontes para estudar temáticas que, embora não se prendam às pesquisas originais, em momentos posteriores fazem apelo ao leitor das narrativas. Homens e mulheres entrevistados para as duas pesquisas aqui focalizadas, mesmo não explicitamente indagados sobre o tema, manifestaram-se (por acaso?), por muitas vezes, quanto a diversos aspectos das relações de gênero envolvidas nas trajetórias dos cursos que formaram/formam professores de Matemática na Univale e na Unimontes.

Neste trabalho, percebemos esses cursos na perspectiva de Louro (2000), isto é, como espaços generificados, por envolver práticas sociais constituídas e constituintes dos gêneros. Compreendemos o gênero como indicador da construção social e histórica de sujeitos femininos e masculinos, para "[...] acentuar o caráter social das distinções baseadas no sexo" (LOURO, 1995, p. 103). Não estando colocadas como foco dos estudos de Castro e Almeida (2015) e Roque (2019), relações e práticas sociais manifestadas no interior de relações de poder não apenas constituíram e instituíram os sujeitos entrevistados, mas produziram as formas de organização e percepção das instituições educacionais a que estiveram ligados.

Propusemo-nos, portanto, trabalhar a emergência do acaso a partir da produção intencional de documentos oportunizada pela mobilização da História Oral em duas pesquisas concluídas nos últimos cinco anos. 


\section{Sobre o surgimento dos cursos de Montes Claros e Governador Valadares}

\subsection{Montes Claros e o contexto de criação da Funm/Unimontes}

Montes Claros, conhecida popularmente como "a Princesa do Norte", o "Coração Robusto do Sertão" (PEREIRA, 2007, p. 108), está localizada na mesorregião do Norte de Minas. Conforme dados do Instituto Brasileiro de Geografia e Estatística (IBGE), ocupa uma área de $3.569 \mathrm{~km}^{2}$ e tinha, em 2010, uma população de 361.915 habitantes (BRASIL, 2010). Dista $424 \mathrm{~km}$ de Belo Horizonte, capital do estado de Minas Gerais. A cidade surgiu em uma fazenda e cresceu em torno de uma capela às margens do rio Vieira, entre os córregos Vargem Grande e Lages, num local conhecido como "Passagem", por interligar as áreas de mineração e o Nordeste do Brasil. Sua posição geográfica estratégica contribuiu para que se tornasse um importante centro comercial regional. Em 13 de outubro de 1831, foi criada a "Vila de Montes Claros de Formigas" que, em 03 de julho de 1857, foi elevada à categoria de cidade, recebendo o nome de Montes Claros. Sua economia baseava-se, na época, na criação de gado, que atendia às demandas dos distritos mineiros em que havia a extração de ouro (PAULA, 2003; PEREIRA, 2007).

Nos anos 1960, o norte de Minas foi palco de investimentos do Estado prómelhoria de sua infraestrutura - energia, saneamento, transportes, habitação - e a região foi contemplada por políticas desenvolvimentistas do Governo Federal. Desse modo, em 1965, ela foi incorporada ao denominado "Polígono das Secas" (por suas características climáticas e socioeconômicas, semelhantes às do semiárido nordestino), e passou a ser atendida pela Superintendência do Desenvolvimento do Nordeste (Sudene), que tinha como objetivo fomentar o processo de industrialização da região e reduzir as desigualdades macrorregionais. Entretanto, essa questão do desenvolvimento é controversa na visão dos entrevistados frente aos documentos escritos a que tivemos acesso, pois os primeiros aludem às condições de carência e os últimos definem a região como rica.

Não havia na região, até os anos 1960, qualquer iniciativa para a constituição de uma escola superior que pudesse suprir a demanda de formação de professores para atuar no ensino secundário. Essa situação motivou um grupo de mulheres norte mineiras, dentre elas Isabel Rebello de Paula, Dalva Santiago de Paula, Maria da Consolação de Magalhães Figueiredo, Maria Isabel de Magalhães Figueiredo (Baby) e Maria Florinda Ramos Marques, a tomar a iniciativa de criar, em 1964, a Faculdade de Filosofia, Ciências e Letras em Montes Claros. A professora Baby Figueiredo fez o relato ${ }^{11}$ a seguir.

Três anos após Isabel Rebello e Dalva12 terem ido para Belo Horizonte para fazer os cursos de História e Geografia, Mary ${ }^{13}$, en e Florinda ${ }^{14}$ também saímos para fazer cursos, de licenciatura, que não eram assim chamados, mas, cursos de Filosofia, com especificidade em Letras, Pedagogia, História e Geografia. Sentíamos o peso da responsabilidade de sermos privilegiadas, e en digo

\footnotetext{
11 As falas dos entrevistados e entrevistadas das pesquisas aqui focalizadas serão todas apresentadas em itálicos.

${ }^{12}$ A professora referia-se a Dalva Santiago de Paula, também uma das fundadoras da Faculdade de Filosofia, Ciências e Letras (Fafil).

${ }^{13}$ Trata-se de Maria da Consolação de Magalhães Figueiredo, irmã da entrevistada e igualmente uma das fundadoras da Faculdade de Filosofia, Ciências e Letras (Fafil).

${ }^{14}$ Baby falava de Maria Florinda Ramos Marques, outra fundadora da Faculdade de Filosofia, Ciências e Letras (Fafil).
} 
privilegiadas, porque eram as mulheres que saíam para fazer cursos de formação de professores, deixando para trás companheiras que sentiam a mesma vontade, eram igualmente inteligentes pesquisadoras, mas não tinham oportunidade semelhante (CASTRO E ALMEIDA, 2015, p. 24).

Ainda estudantes, jovens acadêmicas em Belo Horizonte, reuniamo-nos várias vezes, na Faculdade de Filosofia, juntamente com alguns dos nossos mestres para discutir a relevância do ensino superior no desenvolvimento regional do norte de Minas (CASTRO E ALMEIDA, 2015, p. 100).

Os primeiros passos para a criação de uma faculdade em Montes Claros ocorreram em agosto de 1963, quando a Fundação Educacional Luiz de Paula, que até então atuava na implantação de cursos ginasiais em cidades da região nas quais só havia escolas primárias, aceitou patrocinar "a criação da primeira escola de nível superior do Norte do Estado e ampará-la até sua incorporação à futura universidade da região" (PAULA, 1987, p. 13).

Entre os anos de 1960 e 1970, houve a intensificação da organização do ensino no Brasil, liderada pelos órgãos governamentais, num movimento denominado desenvolvimentista, o qual ampliou o número de escolas primárias, secundárias e a educação superior, tanto nos grandes centros quanto no interior do país, demandando, ainda, a formação de professores para atuar nesses níveis de ensino (ROMANELLI, 1983). Podemos inferir que a demanda pela formação de professores foi guiada pela expansão do ensino no Brasil, provocando a busca por profissionais que pudessem suprir a carência de docentes para lecionar nas localidades interioranas.

A Faculdade de Filosofia, Ciências e Letras (Fafil), primeira escola de ensino superior do Norte de Minas, foi efetivamente instalada em 1964, com cursos de Geografia, História, Letras e Pedagogia, nas dependências do Colégio Imaculada, espaço cedido pelas Irmãs, que também eram alunas. "Era uma dimensão nova na cidade que, se antigamente passara à História por dar tiros... já, agora, era um centro de cultura” (PAULA, 1973, p. 13).

Em 1966, a Faculdade de Filosofia, Ciências e Letras (Fafil) desligou-se da Fundação Educacional Luiz de Paula (Felp) e integrou-se à Fundação Norte Mineira de Ensino Superior (Funm). Em 1968, somaram-se aos cursos existentes na Fafil os cursos de Matemática, Ciências Sociais e Filosofia. A criação da Fafil/Funm foi decisiva para a profissionalização dos professores de toda a região norte mineira, alcançando inclusive outros lugares do estado de Minas Gerais ${ }^{15}$.

\subsection{Governador Valadares e a emergência do MIT/Univale}

Governador Valadares está localizada no leste de Minas Gerais, faz parte da mesorregião Vale do Rio Doce e, em 2010, segundo dados do Censo desse ano, tinha uma população de 263.689 pessoas. Sua criação se relaciona ao movimento de povoação da

\footnotetext{
15 A Universidade Estadual de Montes Claros (Unimontes) é resultado da transformação da Fundação Norte Mineira de Ensino Superior (Funm), conforme texto da Constituição Mineira de 21 de setembro de 1989, em seu artigo 82, parágrafo $3^{\circ}$, do "Ato das Disposições Constitucionais Transitórias" que diz: "Fica transformada em autarquia, com a denominação de Universidade Estadual de Montes Claros, a atual Fundação Norte Mineira de Ensino Superior" (MINAS GERAIS, 1989). Em 1994, a Unimontes foi reconhecida pelo Ministério da Educação (MEC) como Universidade, por meio da Portaria no 1.116 , de 21/07/94.
} 
Bacia do Rio Doce, que teve início no século XVIII. Na primeira metade do século XIX, às margens do Rio Doce, aos pés do Pico da Ibituruna, surgiu um povoado que, em 1884, passou a ser um distrito subordinado ao município de Peçanha e, em 1937, se tornou um município, que em 1938, recebeu o nome atual: Governador Valadares (IBGE, 1959; COSTA, 1977).

Desde o início, o povoado se configurou como um entreposto comercial para trocas de excedentes da região pelos produtos industrializados vindos do litoral. Inicialmente feito pelo Rio Doce, com a inauguração da ferrovia Vitória-Minas, em 1910, o escoamento do café e de outros produtos passou a ser realizado pele rede ferroviária. Com a queda da produção do café, reflexo da crise que acometia todo o país, começou a exploração dos recursos naturais da região, especialmente a madeira, e a criação do gado de corte. A economia de Governador Valadares passou a ser caracterizada, então, por ciclos extrativistas não sustentáveis, como os de madeira e mica. A pecuária extensiva se expandiu com o êxodo rural ocorrido depois de 1955 e a cidade foi marcada, por fim, pelo fenômeno da emigração, especialmente para os EUA, a partir da década de 1980, devido ao período de estagnação econômica que se deu então (SANTOS, 2014).

Foi na década de 1960, quando a população era de 120 mil habitantes, que passou a circular na cidade, especialmente gerado pela fala das lideranças políticas, um discurso de modernidade, e várias medidas foram tomadas nesse sentido, destacando-se as obras de infraestrutura e reforma urbana. Esse discurso de modernidade reflete o contexto brasileiro da época, no qual o apelo por desenvolvimento e modernização era forte e sedutor e havia pressão internacional, sobretudo dos Estados Unidos, para a adoção de políticas modernizadoras (MOTTA, 2014). Especificamente em 1967, foi implantada a primeira escola de ensino superior em Governador Valadares, o Minas Instituto de Tecnologia (MIT), uma das instituições que veio a formar a atual Universidade Vale do Rio Doce (Univale). Foi nela que se fundou o curso investigado em Roque (2019).

De acordo com dados do IBGE (1970), em 1968, ano em que se iniciaram os primeiros cursos de licenciatura na cidade, Governador Valadares tinha uma população estimada em 124.606 habitantes, com cerca de 70.347 crianças entre 0 e 14 anos e 120 unidades escolares de ensino primário, com 28.065 alunos matriculados. Havia, nessa época, 13 unidades de ensino médio ${ }^{16}$, com 7.414 alunos matriculados. O total de professores que atuava no ensino ginasial, colegial e normal perfazia 282 docentes.

Em 1968, o MIT recebeu a denominação Instituto de Tecnologia de Governador Valadares, em atendimento a uma exigência do Conselho Federal de Educação (CFE) e em 1992, juntamente com outras instituições mantidas pela Fundação Percival Farquhar ${ }^{17}$, deu origem à Universidade Vale do Rio Doce. A intenção inicial era que o MIT ofertasse cursos de Engenharia e em seu primeiro vestibular foram oferecidas vagas para os cursos

\footnotetext{
${ }^{16}$ De acordo com a LDB de 1961, o ensino médio correspondia à escolarização elementar que dava prosseguimento à ministrada na escola primária. Era dividido em dois ciclos, o ginasial e o colegial, e abrangia, dentre outros, os cursos secundários, técnicos e de formação de professores para o ensino primário e pré-primário. Para ingresso no ginasial, requeria-se aprovação no exame de admissão e para o colegial a conclusão do ginasial. Após a LDB de 1971 (Lei 5692), o antigo primário, junto com o ginasial, passou a constituir o $1^{\circ}$ grau e o colegial recebeu o nome de $2^{\circ}$ grau. Com a LDBEN de 1996, o primeiro grau passou a se chamar Ensino Fundamental e o $2^{\circ}$ grau Ensino Médio.

17 A Fundação Percival Farquhar (FPF) foi criada em 1967 como uma entidade civil, de direito privado, sem fins lucrativos, com o objetivo de operar como mantenedora do Minas Instituto de Tecnologia.
} 
de Engenharia Metalúrgica, Engenharia Mecânica e Engenharia de Operações Industriais. De 200 vagas, apenas 93 foram preenchidas, e novos cursos passaram a ser ofertados pela instituição, em caráter de urgência, antes mesmo da aprovação do CFE. Dentre esses cursos, estava o de licenciatura em Matemática.

Algumas motivações para a criação do curso de licenciatura em Matemática no MIT foram apresentadas pelos depoimentos e documentos escritos analisados em Roque (2019): o espaço ocioso gerado pelo não preenchimento das vagas da Engenharia; a falta de professores habilitados na disciplina em Governador Valadares; a ausência, na cidade, de professores aptos a trabalhar no próprio MIT; a necessidade de formar pessoas para atuar na pesquisa básica da área de Ciências Exatas, dando suporte à pesquisa aplicada a ser desenvolvida pelos engenheiros. Além disso, havia a motivação financeira: comparados com as Engenharias, os cursos de licenciatura eram mais baratos e exigiriam da Fundação Percival Farquhar pouco mais do que a contratação de novos professores, especialmente para as disciplinas das áreas das Ciências Humanas. Como era certo que havia interesse da comunidade pelos cursos de licenciatura, conforme levantamento que havia sido feito por outra instituição durante o ano de 1967, a abertura desses cursos representava uma certeza de mais recursos financeiros para a manutenção do MIT e garantia o desenvolvimento dos cursos originalmente pensados para a instituição.

A primeira turma do curso de licenciatura em Matemática ingressou em 1968 e a última em 2005; o último aluno se formou em 2012. Percebe-se que a trajetória do curso teve três diferentes fases: da implementação (1968) até sua conversão, junto com as licenciaturas em Física e Química, em licenciatura curta em Ciências (1977); da licenciatura em Ciências (com habilitações plenas em Matemática, Física e Química) até a obrigatoriedade da plenificação trazida pela Lei de Diretrizes e Bases (1996); de 1997 até a extinção, com a conclusão da graduação dos últimos estudantes (2012).

É interessante ressaltar uma particularidade do curso investigado, que é o tipo de instituição no qual foi criado. Diferentemente da maioria das licenciaturas instituídas no Brasil no mesmo período, fundadas em Faculdades de Filosofia, o curso de Governador Valadares foi estabelecido em um Instituto de Tecnologia, destoando, assim, do padrão de implantação desse curso em outras instituições do Brasil na mesma época.

\section{Perspectivas teórico-metodológicas}

A base para este texto é constituída por entrevistas realizadas em pesquisas lastreadas na metodologia da História Oral, conforme princípios e procedimentos essenciais amplamente divulgados em trabalhos do grupo de pesquisa que integramos Ghoem (Grupo de História Oral e Educação Matemática), a exemplo de Garnica, Fernandes e Silva (2011), Garnica e Martins-Salandim (2016) e Garnica e Vianna (2019). Teceremos, a seguir, algumas considerações em relação a tais aspectos a partir desses e de outros trabalhos voltados para a História Oral. Entrevistas de História Oral originam narrativas veiculadas em áudio e textos que se convertem em fontes historiográficas. Nas pesquisas geradoras das narrativas aqui abordadas, foram feitas gravações em áudio e transcrições das entrevistas. Posteriormente, foram elaboradas versões das transcrições em que as falas foram reordenadas e parcialmente alteradas para abrandar as marcas mais 
fortes da linguagem oral, buscando-se, porém, resguardar o teor do que foi dito. Assim foram engendradas as textualizações das entrevistas, que, eventualmente modificadas pelos entrevistados, foram por eles e elas autorizadas mediante a assinatura de cartas de cessão de direitos.

Colaboradores das entrevistas conduzidas na metodologia da História Oral discorrem sobre suas lembranças. Como se tem comentado inúmeras vezes em trabalhos relacionados à memória, o passado é sempre reconstruído no momento em que homens e mulheres narram acontecimentos pretéritos à luz do presente daquele momento em que fazem seus relatos. Assim, cada narrativa composta dentro da situação de entrevista resulta das escolhas então feitas. Nas investigações enfocadas no presente texto, entrevistados e entrevistadas, ao falar a respeito dos cursos de Montes Claros e Governador Valadares, acabaram por narrar passagens de suas histórias de vida, o que compreende racionalizar o passado conforme ele é desenhado para conduzir a um presente inevitável.

Do imenso repertório de memórias e reações possíveis evocadas pela situação de entrevista, o entrevistado seleciona e organiza certos temas, episódios e lembranças, então comunicados de maneira particular. Sem dúvida, a memória em si é gerada e estruturada de maneira específica, em função da oportunidade de contar uma história de vida e das circunstâncias em que isso acontece. Em outro momento da vida, ou diante de outro interlocutor, é provável que surja uma história bem diferente, com ênfases diferentes (PATAI, 2010, p. 30).

A memória humana trabalha e retrabalha constantemente as experiências pessoais. Não há, como dissemos, uma recuperação exata do passado, mas recortes, seleções, construções, em que a imaginação interfere decisivamente a partir dos interesses, desejos e possibilidades do presente. Haveria especificidades da memória feminina e da masculina? Refletindo acerca das mulheres, Catani et al. (2000) afirmam que existe consenso quanto ao vínculo intrínseco entre a memória, o lugar que a mulher ocupa e os papéis que ela desempenha no espaço social. Se, aparentemente, as mulheres têm lembranças diferentes das dos homens, a diferença não se deve a fatores biológicos, mas aos lugares sociais que ambos ocupam ou ocuparam. A memória é marcada, para homens e mulheres, pelos tipos de papéis sociais desempenhados, em trajetórias constituídas pelo meio socioeconômico e cultural, pelo nível educacional, pela faixa etária, entre outros elementos. Assim, as memórias não são femininas ou masculinas especificamente: elas resultam das experiências de cada pessoa.

Até meados do século passado, notava-se que os registros de lembranças das mulheres privilegiavam nitidamente o que se convencionou chamar "esfera do privado" em oposição à “esfera do público". Sem dúvida, foi depois da segunda metade do século XX que as mulheres ocuparam maciçamente posições profissionais e, no que concerne ao magistério secundário, para o qual os cursos envolvidos nas narrativas aqui abordadas habilitavam, foi desde então que elas se tornaram a maioria. A partir dessa época, no Brasil as mulheres participam intensamente do espaço público, exercendo diversificadas responsabilidades sociais e profissionais, e é nesse contexto que também se movimentam e atuam os homens.

Um aspecto fundamental a ser tratado quando se fala da História Oral, que alicerçou durante muito tempo as críticas aos testemunhos, é a argumentação sobre a 
impossibilidade de se confiar neles devido à subjetividade. A resposta padrão para a questão da factualidade e da exatidão é lembrada por Patai (2010): não existem mentiras em História Oral. Isso significa que o narrador tem a intenção de construir um "eu” para ser apresentado ao mundo, sem necessária analogia com os fatos objetivos da vida. Nesse sentido, seu relato é verdadeiro por expressar verdadeiramente esse "eu". Reconhecemos, pois, que não há memória única e definitiva, e que as várias explicações possíveis para um acontecimento mostram que sempre teremos uma noção parcial dos acontecimentos, situações ou realidades, isto é, as fontes construídas pela História Oral são únicas e parciais (GARNICA; VIANNA, 2019).

As narrativas das entrevistas são relatos autobiográficos que, em um período mais recente, têm sido valorizados no movimento de crescimento do apreço pela subjetividade. Referimo-nos a uma característica do campo da História Cultural, que se preocupa com as sensibilidades, isto é, “[...] as formas pelas quais indivíduos e grupos se dão a perceber, comparecendo como um reduto de tradução da realidade por meio das emoções e dos sentidos" (PESAVENTO, 2012, p. 57). No movimento de renovação historiográfica que trata de novos problemas e objetos, especialmente a partir dos anos 1970, marca-se a consideração necessária de vestígios do passado que anteriormente não eram alvo da atenção dos historiadores.

Para o foco selecionado neste texto, as relações de gênero manifestadas em entrevistas cuja intenção era compreender a trajetória histórica de dois cursos de formação de professores de Matemática, tomamos como base estudos de Louro (1994, 1995), nos quais a autora se refere à emergência do conceito de gênero para indicar a construção social e histórica de sujeitos femininos e masculinos, buscando sublinhar o caráter social das distinções fundamentadas no sexo. Conforme a discussão feita por Louro, trata-se de uma ferramenta teórica potencialmente fértil não somente para as ciências sociais em geral, mas particularmente para a educação e a história da educação. O conceito de gênero não apenas pode provocar novas questões, mas produzir novas respostas para antigas questões, "além de colocar como ativos e visíveis sujeitos que usualmente têm estado escondidos nas análises mais tradicionais" (LOURO, 1994, p. 33).

A historiadora estadunidense Joan Scott (1995) defende o trabalho com o conceito de gênero no sentido de serem observadas as relações entre homens e mulheres.

O termo "gênero", além de um substituto para o termo mulheres, é também utilizado para sugerir que qualquer informação sobre as mulheres é necessariamente informação sobre os homens, que um implica o estudo do outro. Essa utilização enfatiza o fato de que o mundo das mulheres faz parte do mundo dos homens, que ele é criado nesse e por esse mundo masculino (SCOTT, 1995, p. 75).

O aspecto relacional do gênero é ressaltado por Lopes (2011, p. 146), que, além de enfatizar que "[...] um gênero se constitui culturalmente em relação com seu Outro, em presença ou em ausência”, aludindo às relações entre homens e mulheres, chama a atenção para as relações entre gênero, idade, classe social e raça, bem como alerta que os estudos de gênero implicam que se estudem não somente as mulheres, mas também os homens.

Nesse contexto, ganha relevo a abordagem foucaultiana do poder "[...] como uma relação e não como um elemento que se possui, ou se detém" (LOURO, 1995, p. 119). Segundo Louro (1995), essa abordagem contribui para a perspectiva histórica que adota o 
conceito de gênero, já que a admissão de muitas e variadas formas de poder na sociedade abre espaço para a compreensão das disputas de poder entre os gêneros na construção da história. $\mathrm{Na}$ reflexão da autora:

As relações de poder entre homens e mulheres, embora recorrentes, serão sempre carregadas de sentidos próprios de cada sociedade e de seu tempo. Além disso, temos de pensar que essas relações não se caracterizariam como de "mão única", tanto porque o movimento se exerce nas duas direções entre os gêneros, quanto porque ele é atravessado por outras disputas, provenientes de outros "campos de força" que não o do gênero (LOURO, 1995, p. 121).

No presente trabalho, que envolve relatos autobiográficos, é pertinente associar a essas considerações a reflexão de Larrosa $(2004$, p.20) acerca das políticas da autonarração.

O que somos é a elaboração narrativa (particular, contingente, aberta, interminável) da história de nossas vidas, de quem somos em relação ao que nos passa. Essa interpretação tem seu lugar em um constante movimento no qual nossa história se põe em relação significativa com outras histórias. [...] Mas sabemos que o poder atravessa a conversação; que o discurso é uma entidade capaz de uma produtividade infinita, porém na qual se projetam múltiplas operações de solidificação e controle; que as práticas discursivas são também práticas sociais; que o discurso, em suma, tem lugar em instituições e práticas sociais mais ou menos organizadas constituídas em relações de desigualdade, de poder e de controle.

Larrosa destaca, assim, que existem instâncias e relações de poder que fazem com que as narrativas sejam compostas em determinada forma, em determinados contextos e para determinadas finalidades, de modo que a história das práticas discursivas de autonarração é também uma história social e política. Vem daí a importância de considerar os lugares sociais e institucionais em que os relatos autonarrativos são produzidos, reproduzidos, mediados, avaliados e utilizados. Cabe ligar essas considerações às duas pesquisas geradoras dos relatos focalizados neste texto, tendo em mente, ao nos concentrarmos nas manifestações que trazem à luz relações de gênero, que as entrevistadoras, em ambos os casos, foram mulheres professoras que cursavam o doutorado em Educação em uma universidade brasileira.

Sob a perspectiva do gênero, está colocado um contraponto às interpretações biologistas, que viam ou ainda veem nas diferenças sexuais explicações para as habilidades e as posições sociais hierarquicamente distintas de homens e mulheres, já que se destaca sua natureza socialmente construída. Cabe, porém, perceber o gênero como uma categoria dinâmica, em construção e passível de transformação, e considerar que ele tem história, isto é, que o feminino e o masculino se transformam histórica e socialmente.

Importa, ainda, a consciência de que, se o gênero é uma construção social, a sociedade não é capaz de impor unilateralmente atitudes e valores considerados adequados a meninos e meninas de modo que eles e elas os internalizem passivamente. Essa imposição não se faz sobre as pessoas “[...] sem que estes mesmos sujeitos aceitem, rejeitem, contestem, adaptem, enfim, sem que, de múltiplas formas, eles participem desse processo" (LOURO, 1994, p. 42). A autora alerta, pois, para o reconhecimento de que "[...] os sujeitos são ativos e ao mesmo tempo determinados, recebendo e respondendo às determinações e contradições sociais" (LOURO, 1994, p. 36). 
Qual o papel de homens e mulheres nos primeiros momentos da criação das instituições e dos cursos de Governador Valadares e Montes Claros? Como professores e professoras, alunos e alunas atuaram nos dois cursos de licenciatura em Matemática? De que maneira se recordaram de experiências de ensino e aprendizagem nesses cursos? Como as vidas pessoais de professores e professoras, alunos e alunas foram lembradas em vínculo com suas trajetórias nos cursos? Comentaremos, a seguir, aspectos das relações de gênero evidenciados quanto a essas questões nas narrativas dos entrevistados. Embora as questões se interconectem, para efeito de clareza, vamos apresentar o que encontramos em quatro partes da próxima seção.

\section{Aspectos que chamam a atenção quanto às relações de gênero nas trajetórias dos dois cursos}

\subsection{Homens e mulheres na criação das instituições e dos cursos de Montes Claros e Governador Valadares}

Ao analisarmos as ações de homens e mulheres na criação dos cursos de Matemática em Montes Claros e Governador Valadares, percebemos a presença de diferenças significativas no desempenho dos papéis de protagonista e coadjuvante entre homens e mulheres, diferenças essas permeadas por variadas relações de poder.

Yannoulas (2011) propõe dois significados distintos para o termo feminização: um deles refere-se ao peso (quantitativo) do sexo feminino na composição das profissões ou ocupações; o outro articula-se ao significado e valor social das profissões ocupadas por mulheres, permeadas pela ideia de "vocação" e determinismo biológico. Nesse sentido, pressupunha-se que as mulheres estariam aptas ao trabalho docente por sua propensão às práticas do cuidado e à manutenção das relações sociais e familiares. Na criação da instituição de Montes Claros, identificamos, em certa medida, a vocação de um grupo de mulheres que tomou a iniciativa da ação, reforçando o aspecto da feminização na docência. O mesmo tipo de ação parece não ter sido frequente em outras instituições e regiões do país, como é o caso de São Paulo (MARTINS-SALANDIM, 2012).

A inserção das mulheres na docência instaurou concepções de escola, mulher, feminilidade, maternidade, masculinidade que se refletiram nas representações da figura da mulher, mãe e professora. Tais representações, que associam o magistério a características tidas como femininas, têm conotações desqualificadoras do profissionalismo. Alguns depoimentos do trabalho de Castro e Almeida (2015) dão indícios do protagonismo feminino na criação da Fafil em Montes Claros e, por conseguinte, na criação de cursos de licenciatura, entre eles o de Matemática, em que seriam formados homens e mulheres para o exercício da docência. Como foi dito antes, foi o grupo formado pelas professoras Isabel, Dalva, Maria da Consolação, Maria Isabel (Baby) e Maria Florinda o responsável pela iniciativa da implantação da Fafil. Isabel Rebello de Paula e Baby Figueiredo valorizaram esse trabalho em seus relatos, respectivamente apresentados a seguir.

A criação da Fafil em Montes Claros foi uma chama que irradiou e despertou lideranças e sociedade para lutarem pelo estabelecimento da nossa universidade na região. Se a Universidade tivesse uma 
mãe, essa mãe certamente foi, a Faculdade de Filosofia, Ciências e Letras do norte de Minas (CASTRO E ALMEIDA, 2015, p. 238).

Compartilhando um ideal comum - servir a comunidade - o grupo de jovens montesclarenses (algumas recém-graduadas, outras ainda estudando) dedicou-se a um projeto desafiador (CASTRO E ALMEIDA, 2015, p. 242).

$\mathrm{Na}$ época de criação da Fafil, a presença de mulheres era incipiente no ensino secundário, e a docência era exercida por profissionais liberais, cuja formação inicial não era o magistério, mas o bacharelado em Medicina, Direito, Engenharia, conforme asseverou a professora Baby Figueiredo, que acentuou a importância de formar professores num curso voltado para essa tarefa.

E o nosso sonho maior era prover a região de um curso superior, iniciando-se por um curso de formação de professores. Até então os professores, igualmente idealistas, das escolas públicas e particulares, eram profissionais liberais: engenheiros, farmacêuticos, médicos, que, embora dominassem o conteúdo das disciplinas, não possuíam as habilidades didático-pedagógicas (CASTRO E ALMEIDA, 2015, p. 242).

No que diz respeito à formação em Matemática, o professor Juvenal Caldeira Durães reconheceu a colaboração decisiva de uma mulher para a "concretização" da criação do primeiro curso de licenciatura no norte de Minas Gerais, que ocorreu posteriormente à implantação da Fafil.

Procuraram a então diretora da Fafil, Sônia Quadros, que prontamente apoiou o grupo desde que uma comissão fosse criada para ajudar na concretização do curso. Eu, Wandaick, Rametta, Callado e outros entusiasmados com o empreendimento nos juntamos à diretora e comecamos a nos movimentar (CASTRO E ALMEIDA, 2015, p. 80).

Diferentemente do que aconteceu em Montes Claros, em Governador Valadares houve completa ausência de mulheres no grupo que projetou e organizou o MIT, que sediaria a licenciatura em Matemática. Inicialmente, o principal responsável pela criação da instituição foi um brigadeiro aposentado do Centro Técnico Aeroespacial (CTA), George Soares de Moraes, que se mudou para a cidade com o objetivo de auxiliar seu pai na condução de uma usina siderúrgica. Ele se reuniu com um dos sócios dessa usina, Antonio Rodrigues Coelho, e outros homens de negócios, para projetar e financiar os custos para a instalação da instituição por meio da criação da Fundação Percival Farquhar.

Uma das colaboradoras da pesquisa de Roque (2019), Tatiana Castello Branco, ressaltou a participação masculina na criação da instituição.

Foi assim, com uma alegria muito grande, que eu vi surgirem as primeiras iniciativas para se criar curso superior em Governador V aladares. [...] Então, essa é uma história que eu vivi do comecinho. Da cabeça de quem surgiu? Naturalmente vocêjá deve ter encontrado essa referência. O prefeito, Dr. Hermírio Gomes da Silva, o brigadeiro George de Moraes, um paulista que veio para cá para mexer com metalurgia numa sociedade com o senhor Antonio Rodrigues Coelho, que era um farmacêtico local, a turma do Rotary Club ${ }^{18}$. Principalmente o pessoal do Rotary Club, que deu um apoio muito

\footnotetext{
18 O Rotary Club é uma organização que teve início em Chicago, no ano de 1905. A ideia de seu fundador, Paul Harris, era reunir profissionais de diferentes setores a fim de que eles pudessem interagir, fortalecer seus vínculos de amizade $\mathrm{e}$ ajudar diferentes comunidades. Hoje, o Rotary Club conta com mais de 35.000 unidades espalhadas por todas as partes
} 
grande. O senhor Oliveira, que era dono de uma farmácia também, o senhor Laércio Byrro, que eram homens expoentes da época. A maioria comerciantes, porque era o que tinha em Valadares! (ROQUE, 2019, p. 331).

A execução do projeto também foi conduzida por um homem, Talmir Canuto Costa, a convite de George Soares de Morais. Talmir havia sido subordinado a ele no CTA e se mudou para Governador Valadares, em 1967, para trabalhar na implantação do MIT. Os primeiros professores, com exceção dos docentes das disciplinas pedagógicas, eram também todos homens.

As posições ocupadas pelas primeiras funcionárias da instituição, nesse período inicial, eram as de auxiliares do trabalho dos homens; essa situação fica clara pela escolha de uma mulher como a primeira secretária da instituição e de outra como auxiliar de Talmir no acompanhamento do planejamento utilizado na organização do MIT. Talmir comentou o trabalho inicialmente desenvolvido pela secretária, dona Therezinha.

Então comecei do zero em Valadares. Nós começamos ali na avenida Minas Gerais, na Praça Serra Lima, em um escritoriozinho onde ficávamos eu e a dona Therezinha ${ }^{19}$. A Therezinha ficava lá e a gente ficava mantendo contato com pessoas: possiveis alunos e professores, e pessoas que pudessem e quisessem entrar nesse empreendimento. Foi assim que se começou (ROQUE, 2019, p. 309-310).

A inserção de mulheres da sociedade de Governador Valadares na instituição foi realizada por meio de um artifício: a criação da Sociedade de Amigas do MIT (Sodami). Ao falar sobre as primeiras atividades extensionistas da instituição, Talmir descreveu essa sociedade:

Nós criamos algumas coisas que eram da área de extensão. Por exemplo, Academia Valadarense de Letras, era extensão; criamos a Sociedade de Amigas da Universidade, a SODAMI, isso é extensão. [...] O que faziam essas senhoras? Eu precisava que essa mensagem do MIT chegasse à comunidade. Os professores que eu levei daqui para lá eram altamente especializados, então, se eu pegasse um Feynman, um Ruperto Farto, um Aldo Baroni, e levasse para falar para a comunidade, eles não conseguiriam entrar na comunidade que só tinha escolas de nivel do Ensino Médio. [...] $A$ Sociedade de Amigas, que era chamada de Amigas da Universidade, Sodami, era composta de senhoras da comunidade, de prestígio. A instituição dava para elas toda a cobertura, proteção, etc e tal, e elas se apresentavam na colação de grau, nos eventos, nas visitas. Nós tivemos até a visita do vice-presidente do Brasill! Então elas se apresentam e elas é que fazem o meio de campo social. E elas se sentem valorizadas: "Nós somos da universidade" (ROQUE, 2019, p. 312-313).

O comentário de Talmir sugere que, de fato, as mulheres estavam ausentes ou tinham presença insignificante na instituição em seus primeiros anos e que, para o sucesso do empreendimento, era importante encontrar meios de integrar a ele as mulheres de posição social de prestígio na sociedade valadarense da época, em particular as esposas dos mantenedores da Fundação Percival Farquhar.

do mundo e desenvolve ações em saúde, educação, saneamento e assistência social. Fonte: < https:/ /www.rotary.org/pt/ >. Acesso em 18 de Jun. de 2020.

${ }_{19}$ Therezinha Oliveira de Almeida. Segundo Campos (2007), ela trabalhou por 35 anos na Fundação Percival Farquhar, começando suas atividades em 1968, ano em que assumiu o posto de secretária de Talmir Canuto Costa. Posteriormente, assumiu outros cargos na instituição: Chefe da Divisão de Orçamento e Finanças; Assistente da Diretoria de Planejamento, Avaliação e Controle; Chefe da Divisão Financeira e Contábil; Diretora Financeira; Chefe do Setor Financeiro e Contábil. 
Conforme foi comentado, o curso de licenciatura em Matemática não estava previsto originalmente no projeto do MIT, centrado nos cursos de Engenharia, tendo sido criado a partir da pouca demanda por esses cursos, pela possibilidade de aproveitamento de recursos a eles destinados sem muito custo adicional. As mulheres estavam ausentes dos cursos de Engenharia e, portanto, praticamente não participaram da implantação do curso de licenciatura em Matemática.

\subsection{Professores e professoras, alunos e alunas nos cursos de licenciatura em Matemática de Montes Claros e Governador Valadares}

Em Governador Valadares, a instalação, pela primeira vez, de cursos superiores colocava um desafio para os que se empenhavam em tal tarefa: a formação do corpo docente. Inicialmente, houve a tentativa de aproveitar docentes que já atuavam na cidade e, para isso, foi oferecido um curso intensivo para professores do ensino secundário da região, que contemplou as disciplinas Matemática, Física e Química. Não houve êxito, no entanto, no aproveitamento desses professores, porque foram considerados sem experiência em nível adequado para a instituição. A solução foi contratar, para lecionar no MIT, um número grande de profissionais de outras cidades, que, na época, já contavam com instituições consolidadas de ensino superior.

Dentre os nomes de professores citados em diversos pareceres do Conselho Nacional de Educação (CNE) referentes aos primeiros anos da instituição, percebemos que a presença majoritária de homens era uma realidade entre os primeiros docentes. Apenas para as disciplinas pedagógicas havia mulheres indicadas como professoras. Para a licenciatura em Matemática, esse perfil foi mudando à medida que as mulheres formadas no curso passaram a ser contratadas pela própria instituição para compor o quadro docente.

Já no que diz respeito ao corpo discente da licenciatura em Matemática, desde o ingresso da primeira turma, observamos que a relação entre a quantidade de homens e de mulheres se inverte. As mulheres concluintes do curso, em todas as suas fases, perfizeram cerca de $80 \%$ dos formandos. Após as primeiras formaturas no curso de licenciatura, muitos ex-alunos foram contratados como docentes do MIT. Entre os 16 entrevistados do trabalho de Roque (2019), oito mulheres graduadas no MIT/Univale se tornaram professoras da instituição.

Com a prevalência de mulheres entre os concluintes do curso, houve uma mudança de perfil no quadro docente: as mulheres, em minoria na primeira fase, passaram a ter presença majoritária nas últimas fases, tornando-se responsáveis também por disciplinas das áreas específicas. Nas disciplinas da parte pedagógica, não foi evidenciada pela pesquisa a presença de nenhum professor do sexo masculino em qualquer fase do curso.

Foi possível perceber que algumas professoras enfatizaram ter mais proximidade com os estudantes do que os professores. Alguns excertos das falas de Denise Coelho de Queiróz, Marli Elias Pereira e Diva Silva Souza, nessa ordem, atestam isso:

Eu acho que en son amiga, procuro ser amiga dos alunos todos... (ROQUE, 2019, p. 377). 
O aluno considerava o professor uma pessoa da familia. Eu me lembro dos meus aniversários, eram surpresas, às vezes eram dois, três cursos que faziam festa para mim. Eu tenho meu álbum só de festinhas que eles me ofereciam, no meu aniversário. [...] Com relação ao comprometimento, eram alunos que vocêpodia ir em um churrasco, brincar. Eu pintava no meio desses meninos, mas pintava mesmo! Jogava futebol com eles; mas na hora da sala de aula: "Eu sou a professora e você é o aluno." Eles sabiam se colocar no seu devido lugar (ROQUE, 2019, p. 494).

E era muito legal porque na hora que a gente começava a se interessar pelas histórias deles e delas: "Mas vocês fazem o quê? O que é típico nessa cidade? Como é que faz?"; começavam a chegar biscoitos de polvilho para a gente comer, coisas gostosas que eles faziam, coisas especificas da cidade, quiijo, goiabada... (ROQUE, 2019, p. 573).

Implantar uma licenciatura em Matemática em Montes Claros também foi, inicialmente, uma tarefa difícil, porque a cidade não tinha docentes habilitados para lecionar as disciplinas matemáticas, conforme Edson Guimarães, entrevistado de Castro e Almeida (2015) acentuou.

Então nós fizemos a solicitação junto à Funm para a criação do curso de Matemática. A resposta que obtivemos foi que era bem difícil a criação do curso, porque nós não tínhamos professores aqui para um curso superior de Matemática. Seria necessário procurar professores de fora... E foi o que aconteceu... Então, o professor Francisco Bastos Gil, de Belo Horizonte (BH), se tornou o pilar de nosso Curso. E esse curso de Matemática foi criado aqui, basicamente, para suprir a deficiência das escolas no sentido da formação profissional superior dos professores (CASTRO E ALMEIDA, 2015, p. 124).

Um professor de Belo Horizonte, Francisco Gil, foi considerado essencial e, por isso, contratado para ministrar todas as aulas das disciplinas de Matemática no primeiro ano do novo curso. Assim, foi um docente do sexo masculino o protagonista do curso em seus primeiros momentos. Para ministrar as disciplinas do núcleo comum dos cursos de licenciatura da Fafil (Psicologia da Educação, Estrutura e Funcionamento do $1^{\circ}$ e do $2^{\circ}$ graus, Português, Didática, Metodologia Científica), foram aproveitados professores dos cursos de Pedagogia, Letras, Geografia e História, criados anteriormente, em 1964. Nas disciplinas pedagógicas, além de não se fazer sentir a necessidade de trazer profissionais de fora da cidade, havia professoras. O professor Gil foi rememorado como um docente fundamental para a existência do curso, muito rigoroso e organizado em suas aulas expositivas. As palavras sobre Gil proferidas por Maria de Lourdes Ribeiro Paixão, Mariza Guimarães e Rosa Terezinha Paixão Durães, nessa ordem, são apresentadas abaixo.

O professor Gil foi uma das pessoas de maior influência no curso de Matemática, praticamente a pessoa mais forte na criação do curso. Ele era considerado muito experiente e preparado para montar o curso (CASTRO E ALMEIDA, 2015, p. 137).

Sobre nossos professores, me lembro que o Gil era muito exigente. Ele se preparava muito para dar as aulas. A gente sentia que ele tinha segurança no conteúdo e, realmente, não enrolava. Ele marcava os assuntos para estudarmos e a gente tinha que dar conta. Ele dava aulas de Cálculo Integral e Geometria. Eram as duas disciplinas mais pesadas do curso... Ele sempre foi muito didático, o quadro era impecável, as aulas muito boas! (CASTRO E ALMEIDA, 2015, p. 290).

O professor Gil sabia organizar um quadro como ninguém jamais viu. O quadro em que ele escrevia podia filmar. A gente tinha pena de apagar o quadro de tão bonito que era, uma letra maravilhosa... 
A aula dele era excelente. Aquele nasceu pra ser mestre. Nasceu pra ser professor de Matemática. Ele ministrou as disciplinas de Cálculo, Fundamentos, Geometria. Ele carregon o curso nas costas, vamos dizer assim... (CASTRO E ALMEIDA, 2015, p. 279).

Conforme o professor Juvenal Caldeira Durães, em 1971, dos 16 formandos dos 64 ingressantes da primeira turma do curso, apenas quatro eram mulheres. Dessas quatro mulheres, duas tornaram-se professoras do curso; dos doze homens, quatro vieram a ser docentes na instituição que os formou. Porém, nem todos permaneceram lecionando no curso.

Os entrevistados comentaram que os alunos que mais se destacaram nas fases iniciais do curso, homens e mulheres, continuamente foram aproveitados posteriormente como professores do curso de Matemática de Montes Claros. Os seguintes trechos das narrativas de Rosina Rabelo Nuzzi Ribeiro e João Barbosa de Souza ilustram esse aproveitamento.

Fui ao mesmo tempo acadêmica e professora do curso porque, na época, meus professores eram muito sobrecarregados... no segundo ano eu já dava aula para os alunos do primeiro ano. Ministrava todas as disciplinas que precisassem. Eles me pediam e eu dava aula no lugar deles, mas eu não tinha contrato com a FUNM, não. Era voluntária (CASTRO E ALMEIDA, 2015, p. 129).

Para segurar o Curso de Matemática da FAFIL, "importaram" o professor Gil lá de Belo Horizonte. Ele segurava o curso e outros professores, que eram alunos de anos mais adiantados, davam aulas pra gente. Era praticamente colega dando aula pra colega. A carência de professores era muito grande (CASTRO E ALMEIDA, 2015, p. 152).

Um aspecto que chama a atenção nos relatos dos entrevistados do curso de Montes Claros é a ênfase dada à postura de seus professores, o exemplo de organização das aulas e o relacionamento com a turma. Diferentemente da situação percebida em Governador Valadares, não foram notadas diferenças entre homens professores e mulheres professoras no sentido da maior ou menor aproximação dos estudantes e do seu acolhimento. Os antigos alunos retrataram seus professores e professoras como figuras de referência em seu futuro trabalho como docentes. Foi o caso de Edson Crisostomo dos Santos, que disse:

Uma das disciplinas de que eu sempre gostei muito foi Cálculo... Então quando me formei, oprofessor Egidio era o professor de Cálculo. Consegui fechar todas as provas de Cálculo durante o ano. Então, o Egidio me convidou, no ano seguinte, para eu trabalhar com ele em uma das turmas, no curso de licenciatura em Matemática. [...] Outros professores do curso, além do Egídio, me serviram de inspiração, especialmente para men trabalbo na Educação Básica. A professora Rosina, por exemplo, trabalhou Prática de Estágio com a gente e foi muito bom. O professor de Geometria também faria um trabalho muito interessante. Nós tínhamos vários professores que eram exemplos pra gente... (CASTRO E ALMEIDA, 2015, p. 329).

\subsection{Homens, mulheres e Matemática nos cursos de Montes Claros e Governador Valadares}

Características dos estudantes do sexo masculino e feminino relacionadas ao estudo de Matemática marcaram presença em algumas narrativas de alunos e alunas, professores e professoras dessas licenciaturas. 
Um aspecto importante a ser considerado em relação à presença de homens e mulheres na licenciatura em Matemática é que, no final dos anos 1960 e início dos anos 1970, ainda não era generalizada a presença das mulheres nos cursos superiores ${ }^{20}$. O depoimento de Rosa Terezinha Paixão Durães, entrevistada por Castro e Almeida (2015), que se casou com Juvenal, também ex-aluno e entrevistado do curso de Montes Claros, ilustra a situação. Ela se recordou que, para sua mãe, as mulheres não precisavam estudar, pois estavam destinadas a cuidar da casa e dos filhos:

Decidi fazer o Curso de Matemática porque o professor João Luiz de Almeida Filho tinha sido men professor no ginásio e foi ele que, além de Juvenal (que já era meu marido nessa época) me incentivou, me deu muita força para en fažer o curso. Sabe uma pessoa que estudou por amor ao estudo, fui eu. Talvez porque, veja bem, quando en terminei o primário muito novinha, com dez anos de idade, minha mãe, coitada, naquela ignorância dela, dizia: "Ah... Mulher não precisa estudar não, pra que mulher vai estudar, mulher tem que casar, tomar conta de filho, aprender a bordar, costurar, lavar roupa, passar roupa, e realmente ela me pôs para aprender bordado... Em tudo, sabe, ela me punha: pra lavar roupa, cozinhar... E eu, sempre, naquela vontade de estudar, naquele desejo enorme de estudar (CASTRO E ALMEIDA, 2015, p. 275).

Se fazer um curso superior visando a um futuro profissional já era menos valorizado para as mulheres que para os homens, estudar Matemática envolvia conviver com a ideia de um curso "muito difícil" em meio a uma "cultura de medo, de distância", ainda conforme as palavras de Rosina Rabelo Nuzzi Ribeiro, outra entrevistada na pesquisa sobre o curso de Montes Claros. Havia uma distinção, aos olhos da sociedade, entre feminino e masculino quanto a papéis e capacidades (PINSKY, 2018).

Uma dificuldade especial enfatizada tanto nos relatos referentes a Montes Claros quanto naqueles sobre Governador Valadares residia no fato de muitas alunas da licenciatura em Matemática serem egressas do curso normal, que habilitava para o magistério no nível primário. Nas palavras de Dilma Silveira Mourão:

O curso de Matemática era muito pesado. No início, em minha turma, houve uma grande dificuldade porque havia pessoas que tinham feito o curso normal e outras o cientifico, que dava uma base melhor para fazer o curso de Matemática. Esses colegas nos amedrontavam dizendo que nós, que tínhamos feito o "Normal", não daríamos conta, que não aguentaríamos, pois o curso era puxado demais para nós (CASTRO E ALMEIDA, 2015, p. 165).

Em Governador Valadares, os alunos das primeiras turmas da licenciatura em Matemática cursavam as disciplinas específicas juntamente com as turmas de Engenharias e das licenciaturas em Física e Química. As mulheres eram minoria, como foi destacado, e havia estudantes como Tatiana, da primeira turma, e Maria Cristina, da segunda, que eram normalistas diplomadas. Elas comentaram ter tido dificuldades em Matemática durante o curso, atribuindo-as à estrutura curricular que formava professores primários. Maria Cristina Ponciano de Lima e Tatiana Castello Branco refletiram sobre as dificuldades que enfrentaram e disseram:

Eu então, que fiz. o Normal, tive que rebolar para estudar. Para fazer o vestibular en já tinha estudado muito. Então, quando eu entrei, tive que correr atrás, muito, muito! Porque o Normal

\footnotetext{
${ }^{20}$ Pinsky (2018) informa que, em relação à presença como alunos no ensino superior, em 1950 a proporção de homens para mulheres era de 8,6 para 1. Em 1960, o quadro havia sido alterado e a mesma proporção agora era de 5,6 para 1.
} 
ensina a gente a dar aula para o primário e em termos de conbecimentos de Física, Química e Matemática a gente para (ROQUE, 2019, p. 356).

Porque uma das maiores inseguranças que eu tive, de começo, para lecionar e para fazer o curso, é que, como eu disse, fiz. curso normal, não fiz. científico. No curso normal você não dava nada de Matemática, nada. A única matéria era Estatística. (...) Então eu não tinha estudado aquilo que seria a base da Matemática: trigonometria, logaritmo, eu não sabia, nem imaginava o que era isso. Eu fui aprendendo por osmose durante o curso (ROQUE, 2019, p. 339, 340).

Ao falar da insegurança que sentia em relação à Matemática, Maria Cristina Ponciano de Lima pareceu considerá-las agravadas pelo fato de as mulheres serem minoria naqueles primeiros anos:

\begin{abstract}
Quando eu comecei a licenciatura em Matemática, a gente tinha muita aula junto com os meninos da Engenharia. Quando eu fui ser professora, já era separado. Quando eu era aluna, tinha hora que a gente ficava muito perdida, porque a gente estava naquele mundo, nós com 19 anos no meio dos rapazes e, às vezes, a gente não entendia e ficava com vergonha de perguntar. Ai a gente falava assim: "Junô, fala que você não entendeu." (ROQUE, 2019, p. 360).
\end{abstract}

A consideração de que o normal tinha sido o nível escolar máximo atingido anteriormente pelas estudantes, segundo Maria Cristina Ponciano de Lima, levou a um tratamento diferenciado em relação ao sexo feminino pela direção da instituição.

A gente tinha aula junto com os meninos da Engenharia; eu falo os meninos, porque naquela época tinha poucas mulheres; e o Dr. Talmir implantou circuito interno de TV. Então, cada dia era uma turma que assistia aula com ele ou outro professor dentro da sala e as outras turmas assistiam pela TV. Nós, mulheres, que chegamos do Normal, conversamos com ele e falamos: "A gente tem muita dificuldade, porque nós não estudamos Física." Então ele nos concedeu que a gente assistisse todos os dias a aula presencial. Porque os meninos faziam aquela bagunça quando ficavam lá vendo televisão. (ROQUE, 2019, p. 356).

A ex-aluna Dilma Silveira Mourão, que residia na cidade de Francisco Sá, a cerca de $50 \mathrm{~km}$ de Montes Claros, relembrou suas dificuldades no deslocamento para assistir as aulas no início do curso e a atenção especial que lhe foi dada pelo professor Francisco Gil.

Meu professor de Cálculo era o Professor Francisco Bastos Gil. Ele era muito exigente mesmo! Ele tinha muita atenção comigo porque ele via que eu vinha de Francisco Sá... Logo que eu passei no vestibular, en descobri que estava grávida do men terceiro filho... O professor Gil via minha dificuldade para vir estudar. Ele me avisava quando ia acontecer alguma reunião para eu não vir. Uma coisa que ajudou muito, no curso de Matemática, foi que os professores não ficavam naquela cobrança do aluno estar presente... Muitos nem fariam chamada... Se você tinha um bom desempenho, ficava tranquilo... Então, geralmente, eu vinha umas três vezues por semana (CASTRO E ALMEIDA, 2015, p. 309).

Em Governador Valadares, a participação das mulheres professoras foi decisiva na terceira fase do curso (1997-2012), na qual mudanças significativas em sua estrutura curricular e concepção ocorreram a partir da aproximação entre parte do corpo docente e o campo da Educação Matemática. As docentes Albertina e Mariza, colaboradoras da pesquisa, contaram que, por sentirem certo incômodo com o formato do curso, muito teórico e sem interlocução entre as disciplinas específicas e pedagógicas, procuraram 
investir em estudos e participação em eventos num momento em que o campo da Educação Matemática começava a se consolidar no Brasil. Esse momento foi próximo da promulgação, em 1996, da nova Lei de Diretrizes e Bases, responsável por trazer para o debate nacional a discussão sobre novos formatos para a formação de professores.

As narrativas evidenciaram que novas abordagens e práticas passaram a ser utilizadas no curso de Matemática da Univale, com o crescimento da preocupação com a aprendizagem dos estudantes e da consciência de que era necessário mudar primeiro a dinâmica do próprio curso para, então, exigir que os estudantes adquirissem novas práticas como professores. Diferentemente das duas primeiras fases, em que o foco estava na formação específica nos conteúdos matemáticos, na terceira fase o curso de Governador Valadares se voltou predominantemente para a formação do professor da Educação Básica.

É interessante destacar, contudo, que nem todos os docentes eram favoráveis à maneira como o curso passou a ser conduzido na terceira fase. Revelou-se, claramente, a existência de divergências entre aqueles que atribuíam maior importância à formação específica em Matemática e aqueles que defendiam a formação pensada do ponto de vista da docência em Matemática. Embora não seja possível fazer generalizações a partir dos testemunhos dos entrevistados, cabe ressaltar que, nos depoimentos, um professor do sexo masculino foi apontado como o principal representante, na instituição, dos adeptos da primeira concepção, ao passo que as mulheres tiveram papel especial na defesa da segunda concepção.

\subsection{Vidas pessoais de professores e professoras, alunos e alunas em Montes Claros e Governador Valadares}

Enquanto a pesquisa referente ao curso de Montes Claros utilizou os depoimentos de um número igual (oito) de homens e mulheres, perfazendo um total de 16 entrevistas, para a investigação sobre Governador Valadares, com igualmente 16 entrevistados, o número de mulheres (14) foi muito superior ao de homens. Não houve intenção prévia, em qualquer dos trabalhos, em estabelecer quantidades fixas de colaboradores do sexo masculino ou feminino. As escolhas foram realizadas, principalmente, a partir de indicações feitas por ex-alunos ou alunas e/ou professores/professoras conhecidos (as) anteriormente pelas pesquisadoras. Como dissemos anteriormente, os roteiros das entrevistas não contemplavam aspectos da vida pessoal dos colaboradores. Assim, alguns se limitaram a falar sobre os temas explícitos nos roteiros, mas houve aqueles que se detiveram em relatar acontecimentos de sua vida pessoal, não diretamente relacionados ao tema da pesquisa. Perceber que essas pessoas se sentiram à vontade para abordar esses assuntos foi interpretado por nós como um indício de que relacionamentos de confiança foram estabelecidos entre entrevistadoras e entrevistados.

$\mathrm{Na}$ pesquisa de Roque (2019), seis dos entrevistados não fizeram referência a aspectos de sua vida pessoal para além dos que envolvem questões acadêmicas e profissionais, dentre os quais estão os dois homens. Talmir Canuto Costa pediu acesso ao roteiro dias antes da entrevista e, ao ser entrevistado, mostrou ter elaborado previamente sua fala a partir das questões que lhe tinham sido enviadas. Seu relato, bem como o de 
Oziel de Souza, o outro homem entrevistado, não incluiu qualquer menção à sua vida pessoal e familiar.

Das 14 mulheres entrevistadas, apenas quatro não explicitaram comentários sobre suas vidas pessoais. As outras dez falaram, durante a conversa sobre a trajetória da licenciatura em Matemática de Governador Valadares, de vivências da infância, de seus pais, especialmente da figura paterna, de irmãos, maridos e filhos.

Tatiana Castello Branco e Marli Elias Pereira, por exemplo, ao iniciar sua apresentação, referiram-se a seu contexto familiar e a situações de sua infância, conforme os trechos de suas respectivas narrativas transcritos a seguir.

Eu sou filha de um pai carioca e de uma mãe mineira. Meu pai veio do Rio de Janeiro na década
de 40, tentando trabalhar com minerais. Esteve empregado em uma empresa de americanos que
estavam aqui explorando mica. Conheceu minha mãe, casaram-se e depois de um ano eles voltaram
para o Rio de Janeiro, já levando minha irmã mais velha. E minha mãe veio aqui, para eu nascer
aqui, em 1947, sem luz, sem recursos, sem hospital, porque não tinha parentes no Rio de Janeiro.
Ela tinha a menininha pequena e quis virpara perto da mãe. Então, eu sou nascida em Governador
Valadares, mas fui criada no Rio de Janeiro. Eu vim para cá já com 13, 14 anos. (ROQUE,
2019, p. 329).

Meu nome é Marli Elias Pereira, sou natural de Governador V aladares, nasci em 22 de abril de 1944 e sempre residi em Valadares. Minha familia era uma familia que tinha uma classe social melhor, mas meu pai quebrou, passamos para uma classe bumilde e fomos morar em um bairro que nem energia elétrica tinha. Por causa disso, eu precisei parar de estudar quando tinha dez aninhos. Porque naquela época não existia escola gratuita e meu pai, com dez filhos, não podia pagar a escola e, por isso, todos tiveram que parar de estudar, inclusive uma irmã que estudava fora, em Belo Horizonte. Eu comecei a trabalhar com meu pai na cerâmica. Meu pai era ceramista e eu ajudava na cerâmica (ROQUE, 2019, p. 481).

Outra das entrevistadas da mesma pesquisa, Denise Coelho de Queiroz, ao comentar sobre as dificuldades que enfrentou para escrever sua dissertação de mestrado, localizou essa dificuldade em acontecimentos de sua vida de criança.

\footnotetext{
Mas essa dificuldade vem de infância, toda vida tive dificuldade atépara falar. Tem algumas palavras que eu não consigo falar bem. Tanto que fui para a escolinha bem mais cedo porque eu não falava nada certo, falava tudo errado. Mas ai tem uma história: lá em casa, a diferença da primeira filha para a última é de 2 anos e 3 meses, e eu sou a do meio. Então eram três bebês. A caçula adoecen e mamãe teve que ir com ela para Belo Horizonte. O papai, para não ficar com duas meninas, uma de seis e outra de sete, nos deixava na casa de parentes para tomar conta da gente e ajudar na escola. Nós moramos dois anos na casa de parentes e no final de semana ele pegava a gente para passear. Então en acho que isso agravou mais. Eu gostava mais de Matemática. O dever de Matemática faria rapidinho, o de Português en enrolava. E como en estava na casa de parente, não era minha mãe que estava me ensinando, dizৃiam: "Ah, depois você faæ:" Isso foi agravando também. Eu tinha muita dificuldade em Português, todo ano tinha que fazer aula particular de Português, então fui ficando com mais trauma. Porque eu acho que se você não gosta e é obrigado a fažer várias coisas daquilo, parece que vai bloqueando. Eu tive essa dificuldade (ROQUE, 2019, p. 380).
}

Adversidades da vida familiar em determinado momento, segundo Juliana Pena Troncozo, outra ex-aluna, repercutiram em sua trajetória estudantil. Onze anos depois, foram recordados na entrevista concedida por ela para a investigação sobre o curso de Governador Valadares. 
E no primeiro semestre de 2006 meu pai acidentou, ficou 40 dias em coma, em São Paulo, e minha mãe precisou ir para lá. Então, ficamos só eu e minhas duas irmãs aqui. E eu tinha que trabalhar na barraca da minha mãe, lá no Beco do Canguru², para poder gerar o recurso financeiro para pagar as contas da casa e continuei no meu emprego também (ROQUE, 2019, p. 472).

$\mathrm{Na}$ investigação sobre o curso de Montes Claros, como dito antes, o roteiro versava sobre aspectos ligados à formação e atuação dos entrevistados e ao curso; porém, há relatos de situações da vida pessoal de homens e mulheres. Baby Figueiredo, uma das fundadoras da Fafil, na qual futuramente se inseriria o curso de licenciatura em Matemática, ao recordar os acontecimentos ligados à criação da instituição, vinculou-os à sua juventude idealista por abrigar o sonho de participar do estabelecimento da educação superior em sua região natal.

Mary e eu, ainda na universidade, aos dezenove anos, já pensávamos em sermos úteis à sociedade. Dezenove anos é uma idade em que a pessoa está pensando em ser útil a si mesma. Útil no sentido do hedonismo, da busca do prazer, da satisfação pessoal, da realização de sonhos... E o nosso sonho maior era prover a região de um curso superior, iniciando-se por um curso de formação de professores (CASTRO E ALMEIDA, 2015, p. 240).

O início do curso de Matemática foi associado ao passado de jovem professor de Francisco Bastos Gil, o docente de Belo Horizonte contratado para viabilizar o oferecimento das disciplinas de conteúdo específico na época exigidas pela legislação educacional, que relatou ter aceito o convite que lhe fizeram, em grande parte, por ser financeiramente vantajoso. Conforme suas palavras,

Pensei muito e decidi estudar a proposta deles... Então me puseram num avião com a minha mulher,
porque não queriam que eu conhecesse a estrada, que era completamente de terra de Curvelo até
Montes Claros. Desci em Montes Claros... Fui muito bem recebido pelas professoras Baby, Mary,
Sônia e pelo próprio W andaick. Fizemos umas reuniões e eles me ofereceram... não me lembro mais
qual era a moeda da época... mas me ofereceram mil e eu trabalhando em Belo Horizonte iria ganhar
apenas trezentos e sessenta. Então, achei que era uma vantagem. Eu tinha 23 anos, recém-formado,
casado e já com uma filha. Mudei-me para Montes Claros (CASTRO E ALMEIDA, 2015, p.
252).

A professora Rosa Terezinha Paixão Durães, aluna da primeira turma do curso, que era casada com outro dos ex-alunos, Juvenal, mostrou-se grata especialmente a ele pela contribuição para vencer as dificuldades iniciais em relação à Matemática.

Eu agradeço a Deus por ter conseguido faz̧er esse curso, porque naquela época eu já era casada, já tinha meus filhos, já trabalhava... Não foi nada fácil! Então, tenho que agradecer muito a Deus... Agradecer a todos que passaram por minha vida naquela época, os professores. E agradeço demais ao Gil, ao Juvenal - meu marido - que me deu essa oportunidade... Ele me ajudou muito, primeiro, porque ele me deu a base que eu precisava, estudou comigo durante um ano para o Curso de Admissão... Por causa dessa base que en tive, en sabia resolver frações, problemas... Ia lá em casa para me namorar, mas, primeiro, ele me ensinava, cobrava de mim, ele também sabia separar as coisas. Se en já gostava de estudar, se eu já gostava da Matemática, eu passei a gostar muito

\footnotetext{
${ }^{21}$ Beco do Canguru é um espaço comercial localizado no centro de Governador Valadares que, além de lojas, possui algumas barracas onde são vendidos itens como roupas, acessórios para casa, peças de artesanato etc.
} 
mais, porque a gente gosta muito daquilo que a gente começa a aprender [...] (CASTRO E ALMEIDA, 2015, p. 282).

É interessante registrar que foi um professor do sexo masculino, Sebastião Alves de Souza, o único que, na pesquisa sobre Montes Claros, relatou problemas pessoais que se refletiram em dificuldades sérias em seu percurso na licenciatura.

Fui considerado o melhor aluno do curso de Matemática no $1^{\circ}$ ano, das duas turmas que entraram, de quarenta alunos... Mas, no final do $1^{\circ}$ ano, aconteceu um acidente em que morreu toda a familia do meu melhor amigo e ele junto. No $2^{\circ}$ ano, foi uma desestrutura total... Continuei sendo o melhor aluno de Quimica, mas, com notas quarenta e cinco, trinta e cinco em cada bimestre que valia cem... Não tinha trabalho, era só prova. A prova valia cem. Em Matemática tirei trinta no $1^{\circ}$ bimestre e zero no $2^{\circ}$, então foi uma crise... Fiquei muito tempo com esgotamento nervoso, estresse, depressão e, logo depois, em agosto do mesmo ano, comecei a lecionar no noturno, além do meu trabalho diário durante o dia [...] (CASTRO E ALMEIDA, 2015, p. 342).

\section{Reflexões finais}

Nas páginas anteriores, procuramos mostrar como, ultrapassando as intenções originais de investigações focalizadas nas trajetórias de dois cursos de formação de professores e professoras de Matemática em Minas Gerais, homens e mulheres entrevistados para essas pesquisas incluíram, em suas narrativas, passagens em que vieram à tona aspectos das relações de gênero em grupos sociais específicos formados por professores e professoras e antigos alunos e alunas. Esses aspectos emergiram das entrevistas de maneira inesperada, imprevista, acidental, quando sujeitos femininos e masculinos foram solicitados a falar de suas experiências relacionadas aos cursos de licenciatura em Matemática de Montes Claros e Governador Valadares. Na leitura que realizamos dos depoimentos, percebemos que algumas práticas sociais constituídas e constituintes dos gêneros foram valorizadas por alguns sujeitos e incluídas em seus relatos.

O termo "acaso" é portador de uma enorme multiplicidade de significados e tem sido debatido por milênios, como comentam várias obras e dicionários de filosofia. Entre esses muitos significados, procuramos trabalhar a ideia de acaso como acidente, em oposição à intencionalidade ou à expectativa. A ocorrência de trechos dos relatos de entrevistados de duas pesquisas nos quais se visibilizaram relações de gênero tocou as autoras e seus interesses, mas não poderíamos prevê-la e não a havíamos desejado de antemão. Quando as pessoas entrevistadas foram indagadas acerca de suas lembranças sobre os cursos de licenciatura em Matemática em que foram docentes ou discentes, não pretendíamos que discorressem sobre alguns temas aqui postos em evidência. Assim, pareceu-nos pertinente considerar que foi "por acaso" que esses temas se fizeram presentes naquele momento e a ideia de escrever este capítulo também nos pareceu pertinente à proposta deste livro.

Decorridos alguns poucos anos após as entrevistas, revisitamos as textualizações em busca de práticas culturais presentes nos espaços das instituições e cursos investigados que sinalizassem relações de gênero participantes daqueles contextos. Anotamos, sublinhamos, comparamos, refletimos, escolhemos, organizamos alguns trechos para 
apresentar ao leitor. Esperamos (não por acaso) ter conseguido mostrar a potencialidade de estudar cursos de licenciatura em Matemática e instituições universitárias responsáveis por eles como espaços generificados.

\section{Referências}

BRASIL. Censo 2010. Diário Oficial da União, Brasília, DF, 04 nov. 2010.

CAMPOS, A. Fundação Percival Farquhar: 1967-2007: 40 anos de ações relevantes. Governador Valadares: Edição do autor, 2007.

CASTRO E ALMEIDA, S. P. N. de. Um lugar, muitas histórias: o processo de formação de professores de Matemática na primeira instituição de ensino superior da região de Montes Claros/norte de Minas Gerais (1960-1990). 2015. 403 f. Tese (Doutorado em Educação) - Programa de Pós-graduação em Educação, Universidade Federal de Minas Gerais, Belo Horizonte, 2015.

CATANI, D. B.; BUENO, B. O.; SOUSA, C. P. de; SOUZA, M. C. C. C. de. História, memória e autobiografia na pesquisa educacional e na formação. In: CATANI, D. B.; BUENO, B. O.; SOUSA, C. P. de.; SOUZA, M. C. C. C. de. Docência, memória e gênero: estudos sobre formação. São Paulo: Escrituras, 2000. p. 15-47.

COSTA, E. C. Epopéia dos Pioneiros: a História de Governador Valadares. Belo Horizonte: Ed. JM, 1977.

GARNICA, A. V. M.; VIANNA, C. R. Oral History in Mathematics Education: an overview. In: GARNICA, A.V.M. (Org.). Oral History and Mathematics Education. 1. ed. New York: Springer, 2019. p. 01-20.

GARNICA, A. V. M.; FERNANDES, D. N.; SILVA, H. da. Entre a amnésia e a vontade de nada esquecer: notas sobre regimes de historicidade e História Oral. Bolema, Rio Claro, v. 25, n. 41, p. 213-250, dez. 2011.

GARNICA, A. V. M.; MARTINS-SALANDIM, M. E. História e Educação Matemática: perspectivas e um projeto coletivo. In: RODEGHERO, C. S.; GRINBERG, L.; FROTSCHER, M. História oral e práticas educacionais. Porto Alegre: Editora da UFRGS, 2016. p. 181-204.

IBGE. Instituto Brasileiro de Geografia e Estatística. Enciclopédia dos Municípios Brasileiros. Rio de Janeiro, 1959. v. 25. p. 156 - 162. Disponível em:

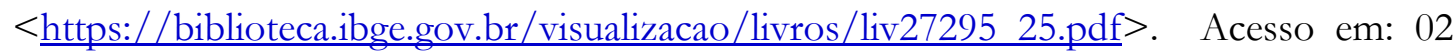
dez. 2017. 
Instituto Brasileiro de Estatística. Coleção de Monografias no 476. 2.ed. Rio de Janeiro, 1970. Disponível em:

< https://biblioteca.ibge.gov.br/visualizacao/periodicos/113/col mono n476 governa dorvaladares 2ed.pdf>. Acesso em: 02 dez. 2017.

LARROSA, J. Notas sobre narrativa y identidad (A modo de presentación). In: ABRAHÃO, M. H. M. B (org.). A aventura (auto)biográfica: teoria e empiria. Porto Alegre: EDIPUCRS, 2004. p. 11-22.

LOPES, E. M. T. Pensar categorias em História da Educação e Gênero. In: LOPES, E. M. T. L.; PEREIRA, M. R. (orgs.). Conhecimento e inclusão social: 40 anos de pesquisa em Educação. Belo Horizonte: Editora UFMG, 2011. p.139-151.

LOURO, G. L. Gênero e magistério: identidade, história, representação. In: CATANI, D. B.; BUENO, B. O.; SOUSA, C. P. de.; SOUZA, M. C. C. C. de (orgs.). Docência, memória e gênero: estudos sobre formação. São Paulo: Escrituras, 2000. p. 77-84.

- Gênero, história e educação: construção e desconstrução. Educação e Realidade, Porto Alegre, v. 20, n. 2, p. 101-120, jul./dez. 1995.

- Uma leitura da história da educação sob a perspectiva do gênero. Projeto História, São Paulo, vol. 11, p. 31-46, nov. 1994.

MARTINS-SALANDIM, M. E. A interiorização dos cursos de Matemática no estado de São Paulo: um exame da década de 1960. 2012. 379 f. Tese (Doutorado em Educação Matemática) - Instituto de Geociências e Ciências Exatas, Universidade Estadual Paulista, Rio Claro, 2012.

MINAS GERAIS. Constituição (1989). Constituição do Estado de Minas Gerais, 1989. Belo Horizonte, MG: Assembleia Legislativa do Estado de Minas Gerais, 1989 Disponível em:

< https://www.almg.gov.br/export/sites/default/consulte/legislacao/Downloads/pdfs/ ConstituicaoEstadual.pdf.> Acesso em: 05 jan. 2021.

MOTTA, R.P.S. As Universidades e o Regime Militar: cultura brasileira e modernização autoritária. Rio de Janeiro: Zahar, 2014.

PATAI, D. História oral, feminismo e política. São Paulo: Letra e Voz, 2010.

PAULA, A. M. N. R. de. Integração dos migrantes rurais no mercado de trabalho em Montes Claros, Norte de Minas: a esperança de melhora de vida. Uberlândia-MG, 2003. 159 f. Dissertação (Mestrado em Geografia) - Instituto de Geografia, Universidade Federal de Uberlândia, Uberlândia, 2003. 
PAULA, I. R. de. Pequena Resenha Histórica da Fafil. Revista Vínculo, Montes Claros, Ano I, n. 01, p. 9-12, mar. 1973.

Fafil: seus ideais e o seu compromisso, suas necessidades, seus valores. Revista Vínculo, Montes Claros, n. 03, p. 5-9, fev. 1987.

PEREIRA, A. M. Cidade Média e região: o significado de Montes Claros no Norte de Minas. 2007. Uberlândia. 351 f. Tese (Doutorado em Geografia) - Programa de Pósgraduação em Geografia, Universidade Federal de Uberlândia, 2007.

PESAVENTO, S. J. História \& História Cultural. 3. ed. Belo Horizonte: Autêntica, 2012.

PINSKY, C. B. Mulheres dos anos dourados. In: DEL PRIORE, M.; PINSKY, C. B. História das mulheres no Brasil. 10. ed. São Paulo: Contexto, 2018. p. 607-639.

ROQUE, A. C. C. A formação de professores de Matemática no curso do MIT/UNIVALE: marginalidade, protagonismo e extinção (Minas Gerais, 1968-2012). 2019. 2v., enc., il. Tese (Doutorado em Educação) - Programa de Pós-graduação em Educação, Universidade Federal de Minas Gerais, Belo Horizonte, 2019.

ROMANELLI, O. de O. História da Educação no Brasil (1930-1973). 3. ed. Petrópolis: Editora Vozes LTDA, 1983.

SANTOS, W.F. A Invenção da Cidade: Governador Valadares na trilha da modernização (1960-1970). 2014. 95f. Dissertação (Mestrado em História) - Instituto de História, Universidade Federal de Uberlândia, Uberlândia, 2014.

SCOTT, J. Gênero: uma categoria útil de análise histórica. Educação e Realidade, Porto Alegre, v. 20, n. 2, p. 71-99, jul./dez.1995.

YANNOULAS, S. Feminização ou feminilização? Apontamentos em torno de uma categoria. Temporalis, Brasilia, v. 11, n. 22, p. 271-292, jul./dez. 2011. 